Abstract PS4:81 Table 1 Quality of life in woman with SLE and RA achieving pregnancy (AP) and not achieving pregnancy (NAP), reported as mean (SD)

\begin{tabular}{|c|c|c|c|c|c|c|c|c|}
\hline Domain & $\begin{array}{l}\text { SLE } \\
\text { AP } \\
n=47\end{array}$ & $\begin{array}{l}\text { SLE } \\
\text { NAP } \\
n=6\end{array}$ & $\begin{array}{l}\text { P- } \\
\text { value }\end{array}$ & $\begin{array}{l}\text { Change } \\
\text { score }\end{array}$ & $\begin{array}{l}\text { RA } \\
\text { AP } \\
n=130\end{array}$ & $\begin{array}{l}\text { RA } \\
\text { NAP } \\
n=50\end{array}$ & $\begin{array}{l}\text { P- } \\
\text { value }\end{array}$ & $\begin{array}{l}\text { Change } \\
\text { score }\end{array}$ \\
\hline Physical function & $\begin{array}{l}90.2 \\
(13.5)\end{array}$ & $\begin{array}{l}80.8 \\
(21.1)\end{array}$ & 0.33 & -9.4 & $\begin{array}{l}80.1 \\
(19.8)\end{array}$ & $\begin{array}{l}78.9 \\
(22.1)\end{array}$ & 0.74 & -1.2 \\
\hline missing & s & 0 & & & 19 & 6 & & \\
\hline Physical Role & $\begin{array}{l}65.2 \\
(40.7)\end{array}$ & $\begin{array}{l}45.8 \\
(40.1)\end{array}$ & 0.28 & -19.4 & $\begin{array}{l}58.9 \\
(40.4)\end{array}$ & $\begin{array}{l}57.4 \\
(45.0)\end{array}$ & 0.85 & -1.5 \\
\hline missing & 5 & 0 & & & 19 & 6 & & \\
\hline Bodily Pain & $\begin{array}{l}72.5 \\
(23.6)\end{array}$ & $\begin{array}{l}79.0 \\
(31.6)\end{array}$ & 0.55 & +6.5 & $\begin{array}{l}61.8 \\
(24.0)\end{array}$ & $\begin{array}{l}65.4 \\
(25.4)\end{array}$ & 0.42 & +3.6 \\
\hline missing & 5 & 0 & & & 19 & 6 & & \\
\hline Global Health & $\begin{array}{l}60.3 \\
(26.1)\end{array}$ & $\begin{array}{l}56.0 \\
(13.9)\end{array}$ & 0.55 & -4.3 & $\begin{array}{l}57.5 \\
(21.9)\end{array}$ & $\begin{array}{l}57.0 \\
(24.1)\end{array}$ & 0.90 & -0.5 \\
\hline missing & s & 0 & & & 20 & 6 & & \\
\hline Vitality & $\begin{array}{l}50.7 \\
(22.4)\end{array}$ & $\begin{array}{l}42.5 \\
(27.2)\end{array}$ & 0.42 & -8.2 & $\begin{array}{l}48.0 \\
(19.9)\end{array}$ & $\begin{array}{l}50.1 \\
(21.0)\end{array}$ & 0.56 & +2.1 \\
\hline missing & 5 & 0 & & & 19 & 7 & & \\
\hline Social function & $\begin{array}{l}75.0 \\
(24.4)\end{array}$ & $\begin{array}{l}64.6 \\
(27.9)\end{array}$ & 0.34 & -10.4 & $\begin{array}{l}80.6 \\
(22.8)\end{array}$ & $\begin{array}{l}80.4 \\
(21.3)\end{array}$ & 0.95 & -0.2 \\
\hline missing & 5 & 0 & & & 19 & 6 & & \\
\hline Role emotional & $\begin{array}{l}79.4 \\
(36.8)\end{array}$ & $\begin{array}{l}50.0 \\
(46.0)\end{array}$ & 0.082 & -29.4 & $\begin{array}{l}81.7 \\
(32.3)\end{array}$ & $\begin{array}{l}77.3 \\
(35.1)\end{array}$ & 0.46 & -4.4 \\
\hline missing & 5 & 0 & & & 19 & 6 & & \\
\hline Mental health & $\begin{array}{l}74.9 \\
(14.7)\end{array}$ & $\begin{array}{l}68.7 \\
(12.8)\end{array}$ & 0.53 & -6.2 & $\begin{array}{l}77.7 \\
(13.7)\end{array}$ & $\begin{array}{l}80.2 \\
(15.4)\end{array}$ & 0.33 & +2.5 \\
\hline missing & 5 & o & & & 19 & 7 & & \\
\hline
\end{tabular}

(MCID) in all domains except for bodily pain, which was higher. Women with RA had generally lower QoL than women with SLE in the domains physical role, bodily pain and global health whether or not conceiving. The women with RA not achieving pregnancy had higher QoL-scores on bodily pain and lower scores on emotional role, but not differences in scores of clinical relevance in the other domains of QoL compared to RA-women achieving pregnancy (table 1).

Conclusions Reduced quality of life may contribute to not achieving pregnancy in both women with SLE and women with RA.

\section{PS4:82 LUPUS PREGNANCY: ACHIEVEMENTS AND OPEN ISSUES IN THE MULTIDISCIPLINARY MANAGEMENT}

${ }^{1} \mathrm{~F}$ Crisafulli, ${ }^{1} \mathrm{~L}$ Andreoli, ${ }^{1} \mathrm{~L}$ Antolini, ${ }^{1} \mathrm{G}$ Parma, ${ }^{2} \mathrm{C}$ Benigno, ${ }^{3} \mathrm{~A}$ Lojacono, ${ }^{3} \mathrm{~S}$ Zatti,

${ }^{4} \mathrm{~V}$ Cappa, ${ }^{4} \mathrm{~S}$ Calza, ${ }^{1} \mathrm{~A}$ Tincani. ${ }^{1}$ Rheumatology and Clinical Immunology Unit, Spedali Civili and University of Brescia, Italy; ${ }^{2}$ Rheumatology and Clinical Immunology Unit, Federico II University Hospital and Federico II University of Napoli, Italy; ${ }^{3}$ Obstetrics and Gynaecology Unit, Spedali Civili and University of Brescia, Italy; ${ }^{4}$ Biostatistics and Biomathematics Unit and Bioinformatics Unit, Spedali Civili and University of Brescia, Italy

\subsection{6/lupus-2018-abstract.127}

Purpose To analyse the pregnancy outcome of patients with Systemic Lupus Erythematosus (SLE): 
Abstract PS4:82 Table 1 General and SLE-correlated risk factors in 'APO' and 'without APO' groups

\begin{tabular}{|c|c|c|c|}
\hline General risk factors & APO $\%$ & Without APO \% & $P$ value \\
\hline Age $>35$ years & 35,3 & 30,5 & 0,491 \\
\hline Hypertension & 17,6 & 16,1 & 0,722 \\
\hline Diabetes mellitus & 0,0 & 0,8 & 1,000 \\
\hline Obesitiy & 11,7 & 5,9 & 0,712 \\
\hline Thyroid disease & 0,0 & 5,9 & 1,000 \\
\hline Cigarettes smoking & 41,2 & 20,3 & 0,187 \\
\hline SLEDAI $>0$ & 86,7 & 83,9 & 1,000 \\
\hline SLEDAI >6 & 14,3 & 14,8 & 1,000 \\
\hline dsDNA & 84,6 & 62,6 & 0,172 \\
\hline Lupus nephritis & 52,9 & 33,0 & 0,167 \\
\hline Low C3 and/or C4 & 50,0 & 54,6 & 0,790 \\
\hline Ro and/or La & 53,8 & 41,9 & 1,000 \\
\hline $\mathrm{aPL}$ & 64,6 & 51,6 & 0,278 \\
\hline Triple aPL & 23,5 & 11,8 & 0,244 \\
\hline LAC & 23,5 & 21,2 & 0,760 \\
\hline Previous thrombosis & 0,0 & 3,4 & 1,000 \\
\hline Previous APO * & 35,3 & 21,2 & 0,221 \\
\hline
\end{tabular}

${ }^{*} \mathrm{APO}$ were defined as premature miscarriage $\left(<10^{\wedge}\right.$ weeks), fetal death $\left(>10^{\wedge}\right.$ weeks), preterm delivery $\left(<34^{\wedge}\right.$ weeks) with or without preeclampsia, HELLP Syndrome, perinatal death ( $<30^{\wedge}$ day).

1. by comparing the outcome of prospectively-followed pregnancies (PFP) and anamnestic pregnancies (AP);

2. by comparing the outcome of PFP with the general obstetric population (GOP);

3. by evaluating the disease features, maternal risk factors and treatment of pregnancies with adverse pregnancy outcome (APO) in PFP.

Methods A monocentric, retrospective and observational study of 94 SLE patients with a total of 135 pregnancies followed prospectively by multidisciplinary team. In addition, $33 \mathrm{AP}$ in the same SLE patients and 3939 pregnancies among GOP were evaluated. Clinical and serological data were obtained from medical records.

Results The comparison between PFP and AP showed lower frequency of premature miscarriage $(6,7 \%$ vs $27,3 \%$, p value $0,0021)$ and fetal death $(3,7 \%$ vs $36,4 \%$, p value $<0,0001)$ and higher frequency of live birth $(88,9 \%$ vs $36,4 \%$, p value $<0,0001)$ in the first group. As compared with GOP, SLE-PFP displayed similar rate of early miscarriage $(9,0 \%$ vs $6,7 \%)$ and fetal loss $(5,0 \%$ vs $3,7 \%)$ but higher frequency of preeclampsia $(1,0 \%$ vs $5,0 \%$, p value 0,0029$)$, preterm birth $(7,0 \%$ vs $18,4 \%, \mathrm{p}$ value $<0,0001)$ and Caesarian section $(31,0 \%$ vs $41,7 \%$, p value 0,0288$)$.

APO occurred in $17(12.6 \%)$ of the 135 PFP. Despite the lack of statistical significance, there was a tendency toward higher frequency of anti-dsDNA positivity (84,6\% vs 62,6\%), history of lupus nephritis $(52,9 \%$ vs $33,0 \%)$ and triple antiphospholipid antibody (aPL) positivity $(23,5 \%$ vs $11,8 \%)$ in pregnancies with APO (table 1). Analysing treatment during pregnancy, the group with APO received higher doses of prednisone (without significant $\mathrm{p}$ value) and required higher use of immunosuppressants $(64,7 \%$ vs $31,3 \%$, p value 0,032$)$.

Conclusions The outcome of PFP in SLE has dramatically improved as compared to AP, thanks to pregnancy planning, multidisciplinary management and close monitoring during pregnancy. The occurrence of APO was restricted to a minority of PFP $(12,6 \%)$. SLE-PFP had similar rates of pregnancy losses as compared to GOP, but there are still open issues on some pregnancy complications that affect SLE patients more frequently.

\section{PS4:83 FOLLOW-UP OF NEWBORN BABIES FROM MOTHER AFFECTED BY SYSTEMIC AUTOIMMUNE DISEASE}

${ }^{1}$ Tiziana Bertero, ${ }^{2}$ Jessica Munarin, ${ }^{2}$ Mario Frigerio, ${ }^{2}$ Emilia Parodi. ${ }^{1} /$ mmunology Unit, ASO Mauriziano Hospital, Torino, Italy; ${ }^{2}$ Pediatric and Neonatology Unit, ASO Mauriziano Hospital, Torino, Italy

\subsection{6/lupus-2018-abstract.128}

Introduction Most autoimmune systemic diseases affect more frequently females in reproductive age, suggesting the need to consider the possible effect on some important aspects of women's life such as fertility and pregnancy, but above all possible outcomes on the newborn and, subsequently, on the child.

Topic of this study is the analysis of the neonatal and long-term paediatric outcomes, until school age, of a group of paediatric subjects born from mother affected by systemic autoimmune disease, in care at the Department of Neonatology and Paediatrics of the Mauriziano Hospital of Turin, in order to identify any associations with pregnancy and the type and activity of maternal disease.

Materials and methods From October 2016 all women in care at the Department of Immunology of the Mauriziano Hospital, aged between 25 and 45, who had one or more pregnancies hesitated in the birth of alive baby during January 2002 and October 2015, have been enrolled in this study.

We have considered, for each pregnancy $(n=48)$ : type of maternal disease (with antibody dosage), obstetric outcomes (type of delivery, indication to caesarian section, gestational age at birth), neonatal outcomes (Apgar score, low neonatal weight, fetal growth restriction, neonatal complications), clinical-diagnostic management of babies (hematologic and other examinations required) and long-term paediatric outcomes (psychomotor development alterations, chronic diseases, hematologic alterations, hospital admissions). 